\title{
The effects of hypoxia on the excitability of the isolated peripheral nerves of alloxan-diabetic rats
}

\author{
K. N. SENEVIRATNE AND O. A. PEIRIS \\ From the Departments of Physiology and Medicine, Faculty of Medicine, \\ University of Ceylon, Colombo
}

Steiness (1959) observed that diabetic subjects whose lower limbs were rendered ischaemic with a pneumatic cuff around the thigh were able to perceive a vibratory stimulus applied to the toes for longer periods than non-diabetics. In some diabetic subjects the threshold remained almost unchanged during a 30 minute period of experimental ischaemia. Steiness $(1961 \mathrm{a}, \mathrm{b})$ showed that it was not possible to increase the time of perception of the stimulus in normal subjects by inducing hyperglycaemia in them, that the abnormal condition in diabetics was reversible, and that it bore some relationship to the state of control of the diabetes. This resistance of the peripheral nerves of diabetic subjects to ischaemia has been confirmed by Castaigne, Cathala, Dry, and Mastropaolo (1966). Gregersen (1968) studied the effects of limb ischaemia on vibration perception threshold, tactile sensation, pain, heat-induced pain sensation, and motor nerve conduction velocity in healthy and diabetic subjects. His results show that vibration perception, motor nerve conduction velocity, and tactile sensation are relatively unaffected by ischaemia in the diabetic subjects, in contrast to that observed in the normal subjects. The sensations of heat and heat-induced pain, however, remained unchanged during the ischaemia in the diabetics as well as in the control group. Seneviratne and Peiris (1968b) have shown that the evoked sensory nerve action potential of the median nerve of diabetic subjects is resistant to ischaemia produced by vascular occlusion of the upper limb by pneumatic cuff compression. These evoked potentials, in contrast to those of normal subjects, showed a relative constancy of their amplitudes, durations, and latencies during a 30 minute period of complete vascular occlusion. These changes could be demonstrated in all the diabetic subjects studied irrespective of whether or not they had evidence of a neuropathy. None of their diabetic subjects experienced ischaemic or post-ischaemic paraesthesiae, which were a very constant feature of the early ischaemic and postischaemic phases in the control group.
It was postulated that these differences in the behaviour of the nerves of diabetic subjects may have been due to the fact that the metabolites released from the tissues of the diabetic during vascular occlusion were essentially different from those produced by the tissues of normal subjects under similar conditions. Alternatively, there may have been no essential difference between the metabolites produced by the normal and diabetic subjects, the relative resistance of the diabetic nerve being due to its ability to maintain its activity under ischaemic conditions. The experiments described in this paper were designed to study the effects of hypoxia on the excitability of isolated peripheral nerve.

\section{METHODS}

Experimental diabetes was produced in 6-month-old male rats weighing between 100 to $150 \mathrm{~g}$ by a modification of the method described by Klebanoff and Greenbaum (1954). A single dose of alloxan monohydrate (BDH) of $150 \mathrm{mg} / \mathrm{kg}$ body weight in freshly prepared $0.125 \mathrm{M}$ citrate-phosphate buffer at $p \mathrm{H} 4$ was injected intraperitoneally at a concentration of $10 \mathrm{mg} / \mathrm{ml}$. and the rats maintained in separate metabolism cages with free access to food and water. With this dose level 18 of the 50 rats injected died within a few days, 10 became diabetic but regained normal blood glucose levels within two weeks, while 22 rats remained permanently diabetic. The criteria used to establish diabetes in these animals were a blood glucose level of over $200 \mathrm{mg} / 100 \mathrm{ml}$. and a glycosuria of $1 \%$ or more. These animals were maintained for at least four weeks in this condition before being used for study. The duration of the diabetic state in the animals studied varied from four to 20 weeks. Litter mates of these rats, and the alloxanized non-diabetic rats, were maintained under the same conditions and served as controls in all the experiments described below.

ELECTROPHYSIOLOGICAL EXPERIMENTS The rats were anaesthetized with intraperitoneal sodium pentobarbitone (Nembutal) $50 \mathrm{mg} / \mathrm{kg}$ body weight and the sciatic nerves were dissected out rapidly from the level of the sciatic notch to the gastrocnemius tendon. The nerves were cleaned of fat, connective tissue, and blood vessels, but 
the nerve sheath was left intact. The nerve was then immersed in modified mammalian Tyrode's solution buffered to $p \mathrm{H} 7 \cdot 3$ (Maruhashi and Wright, 1967), maintained at $37^{\circ} \mathrm{C}$ in a water bath and exposed to a gas mixture containing $95 \% \mathrm{O}_{2}+5 \% \mathrm{CO}_{2}$ for 15 minutes to minimize any 'injury activity' (Adrian, 1930). After this period the nerve was mounted in a small moist nerve chamber provided with a gas inlet tube and outlet tube containing a valve which maintained a one-way flow. The nerve was laid across platinum stimulating, earth and recording electrodes, so that the proximal end of the nerve lay across the stimulating electrodes and the distal cut end of the nerve lay on the distal recording electrode. The chamber was then made gas-tight by replacing its lid and sealing it with Vaseline. The gas mixtures used in these experiments $\left(95 \% \mathrm{O}_{2}+5 \% \mathrm{CO}_{2}\right.$ and $8 \% \mathrm{O}_{2}+5 \% \mathrm{CO}_{2}$ in nitrogen) were admitted into the chamber after passage through a flowmeter to ensure a constant rate of flow of $250 \mathrm{ml} . / \mathrm{min}$. The gas mixture was led into the nerve chamber after bubbling through a wash bottle containing the modified Tyrode's solution. The wash bottle and the nerve chamber were placed in a water bath maintained at $37^{\circ} \pm 1^{\circ} \mathrm{C}$.

The nerve was stimulated using square-wave stimuli of $0.01 \mathrm{msec}$ duration and variable voltage from a Grass S4 stimulator and RF coupled isolating transformer. The evoked responses were amplified by a Grass P511R RC coupled pre-amplifier with half-amplitude frequencies of $7 \mathrm{c} / \mathrm{s}$ and $2 \mathrm{Kc} / \mathrm{s}$. The amplified responses were monitored through a loud-speaker and displayed on one beam of a Tektronix 502 oscilloscope, the sweep of which was triggered by the stimulator output with negligible delay. The lower beam of the oscilloscope monitored the stimulus through a high impedance probe. Single sweeps of the oscilloscope were photographed on $35 \mathrm{~mm}$ film.

In all the experiments described below a nerve was used for one experiment only and the other sciatic nerve was kept for histology.

Experiment I The nerve was exposed to a $95 \% \mathrm{O}_{2}+$ $5 \% \mathrm{CO}_{2}$ mixture and the response to a supra-maximal stimulus recorded. The stimulus strength was then reduced until the evoked response was approximately $50 \%$ of its maximum value. This stimulus strength was then maintained constant and the response to it recorded at two minute intervals for 30 minutes.

Experiment II The nerve was exposed to the $95 \%$ $\mathrm{O}_{2}+5 \% \mathrm{CO}_{2}$ gas mixture and the stimulus strength required to produce a response nearly $50 \%$ of maximum was determined. The nerve was then exposed to the $8 \%$ $\mathrm{O}_{2}+5 \% \mathrm{CO}_{2}$ in $\mathrm{N}_{2}$ mixture and the responses to this stimulus recorded at two minute intervals.

Experiment III Experiment II was repeated using the nerves of the diabetic animals.

On every occasion experiments II and III were done alternately to ensure that comparable experimental conditions were maintained between the diabetic and the control nerves.

Histology The nerve was attached to a piece of card at its original length, fixed in $10 \%$ formol-saline and stained with $1 \%$ osmium tetroxide. Single fibres were isolated by the method described by Thomas and Young (1949).

\section{RESULTS}

EXPERIMENT I Results obtained from 10 control nerves showed that the evoked response to a submaximal stimulus of constant size did not vary in amplitude by more than $10 \%$ of its original value.

EXPERIMENT II Fifteen nerves from rats of the control group were studied in this series. The results indicate that all the nerves were inactivated by the hypoxia, the response size reducing to less than $10 \%$ of its resting value at times varying from 16 to 25 minutes (mean 21.2 minutes). In all the nerves studied this inactivation was preceded by a phase of hyperexcitability, the response to the stimulus of constant strength increasing to a maximum value of $8 \%$ to $60 \%$ (mean $36.8 \%$ ) above its original size. This maximum size was reached at times varying from two to nine minutes (mean 5.2 minutes $\mathrm{SD} \pm$ 1.7). The evoked responses obtained in one such experiment are reproduced in Fig. 1, while the results obtained from six such experiments are represented graphically in Figure 2.

EXPERIMENT III Fifteen experiments were done with nerves from diabetic animals. The responses obtained in one such experiment are reproduced in Fig. 1, while the results from six experiments are represented in Figure 2. In these experiments there was incomplete inactivation of the nerves by hypoxia. Even after 30 minutes' exposure to the $8 \% \mathrm{O}_{2}$ mixture, the response amplitudes retained from $16 \%$ to $78 \%$ (mean $48 \%$ ) of their original size. As in the control experiments, all the diabetic nerves showed an early phase of hyperexcitability. The maximum increase in response size during this phase varied from $12 \%$ to $54 \%$ (mean $23.9 \%$ ) and occurred between the fifth and fourteenth minute (mean $9 \cdot 1$ minutes SD $\pm 2 \cdot 7$ ). The times at which the responses of the control and diabetic nerves reached their maximum size during the hyperexcitable phase are indicated in Fig. 3 and Table I.

HISTOLOGICAL CHANGES Evidence of segmental demyelination could be found in some of the fibres of the sciatic nerves of all the diabetic rats. The earliest recognizable change was a retraction of the myelin from the nodal region, leading to a conspicuous widening of the nodal gap, associated sometimes with a bulbous swelling of the paranodal region of the fibre. At a later stage the myelin in the internodal region showed evidence of fragmentation, breaking up into ovoids of irregular shape and size and into progressively smaller particles which gave the fibre a coarsely granular appearance. In the internodal regions these myelin particles could often be recog- 


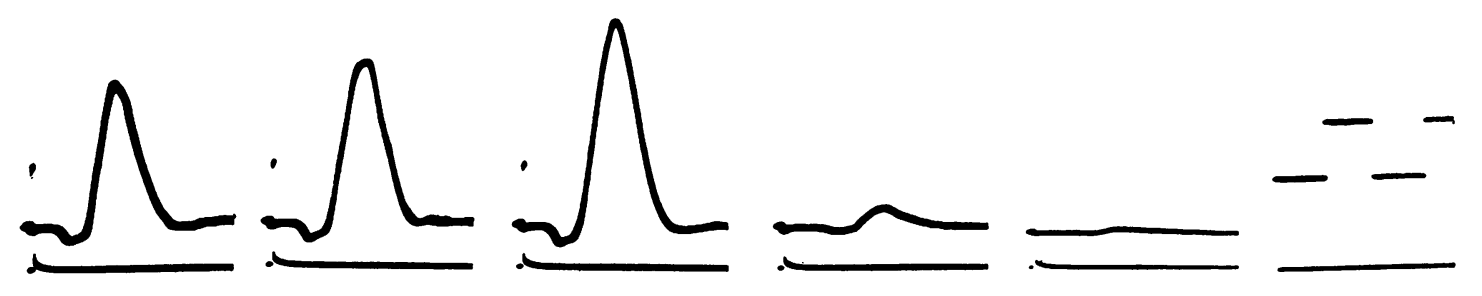

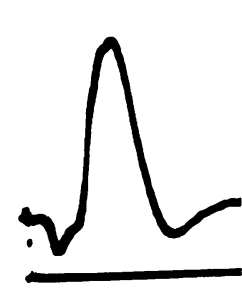

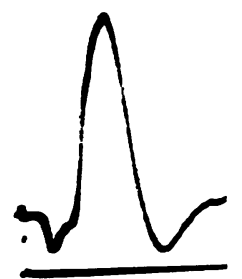

5

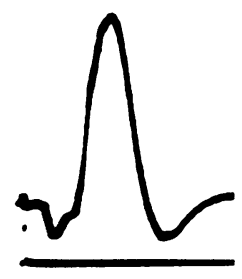

10

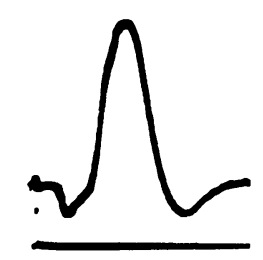

15

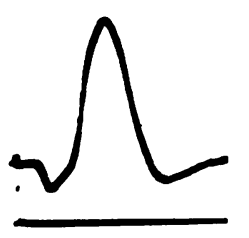

20

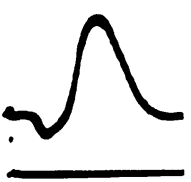

30

FIG. 1. Effects of hypoxia on the compound action potential evoked by a sub-maximal stimulus. Upper row: nerve from control rat. Lower row: nerve from diabetic animal. Figures indicate time in minutes. Upper right corner: calibration trace, square-wave form $1 \mathrm{kHz}, 0.5 \mathrm{mV}$ amplitude.
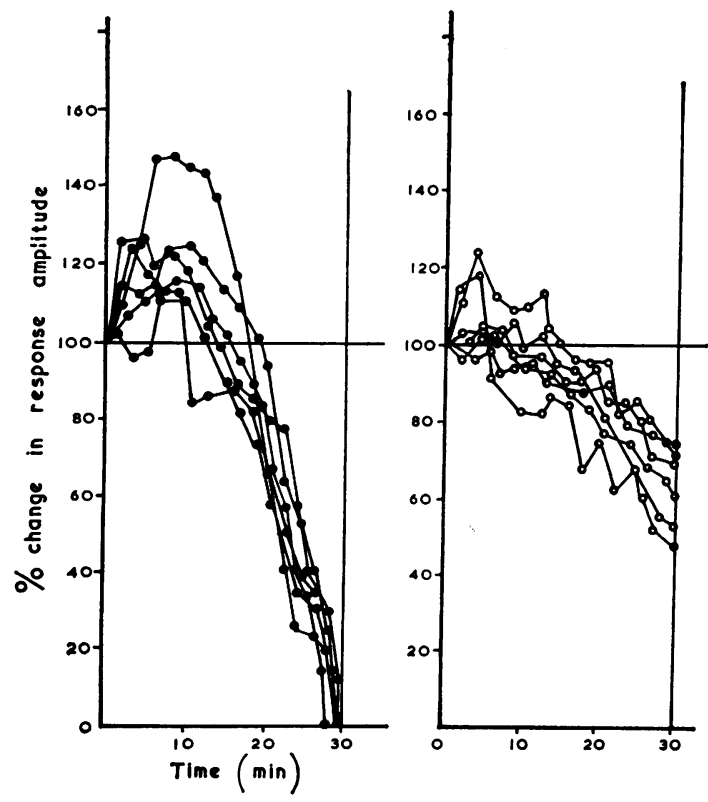

FIG. 2. Results obtained from six control subjects (filled circles) and six diabetic subjects (open circles) showing effect of ischaemia on the human median sensory nerve potential. (Redrawn from data of Seneviratne and Peiris, $1968 a, b)$.

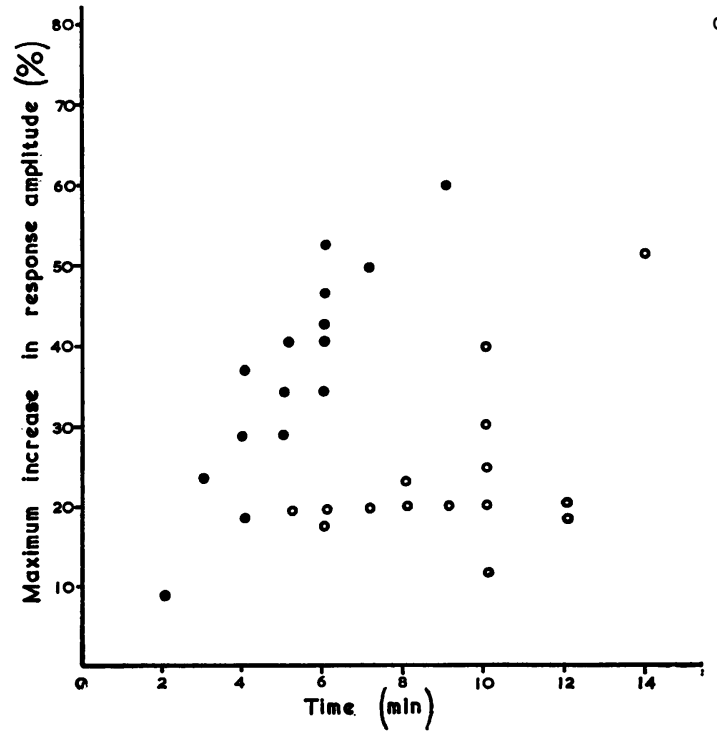

FIG. 3. Time to reach maximum increase of response amplitude. Nerves from control rats (filled circles), diabetic rats (open circles). 
TABLE I

TIME TO REACH MAXIMUM INCREASE OF RESPONSE AMPLITUDE

\begin{tabular}{ccc}
\hline & $\begin{array}{c}\text { Control nerves (15) } \\
(\text { min) }\end{array}$ & $\begin{array}{c}\text { Diabetic nerves (15) } \\
(\text { min })\end{array}$ \\
\cline { 2 - 3 } Range & $2-9$ & $5-14$ \\
Mean & $5 \cdot 2$ & $9 \cdot 1$ \\
SD & $\pm 1 \cdot 7$ & $\pm 2 \cdot 7$ \\
Student's $t$ test & $<0.001$ & \\
Significance $(P)$ & & \\
\hline
\end{tabular}

nized forming granular aggregates condensed around the funnel-shaped Schmidt-Lantermann clefts. Reduction in the size of the myelin granules was associated with a loss of staining density, and short lengths of endoneurial tube devoid of myelin debris could occasionally be recognized (Fig. 5). In multi-fibre preparations several of these stages could be demonstrated in the fibres of a single sciatic nerve, but the smaller diameter myelinated fibres always seemed more adversely affected than those of larger diameter. Although the blood glucose levels of these diabetic animals varied from 300 to $700 \mathrm{mg} / 100 \mathrm{ml}$. and the duration of the diabetic state varied from 30 to 150 days, there was no obvious relationship between the severity or duration of the diabetes and the extent of these histological changes.

\section{DISCUSSION}

Several workers have investigated the structural and functional changes that occur in the peripheral nerves of alloxan-diabetic rats. Segmental demyelination has been observed in these nerves by Preston (1967), Lovelace (1967) and by Hildebrand, Joffroy, Graff, and Coërs (1968), these changes being essentially similar to those observed in human diabetes by Thomas and Lascelles (1966). The histological results reported in this study confirm these observations. All nerves studied had some evidence of demyelination, the early changes being more evident than the late. Only an occasional fibre showed demyelination over a whole internodal segment, or evidence of remyelination as indicated by the presence of shortened internodal lengths. These changes were, however, more marked than those observed by Hildebrand et al. (1968), though not as evident as those described by Preston (1967). Lovelace (1967) was of opinion that the severe early histological changes reported by Preston (1967) could have been due to a toxic effect of the alloxan, not related to the diabetes. Our results are therefore consistent with the fact that all the animals in this series had blood glucose levels varying from 300 to $700 \mathrm{mg} / 100 \mathrm{ml}$, and that the nerves were studied at least four weeks after the injection of alloxan.
There is as yet little information relating to the electrophysiological changes in the peripheral nerves occurring in experimental diabetes. Eliasson (1964) and Lovelace (1967) have reported a decrease in the in vitro conduction velocity of the nerve impulse, while Preston (1967) observed a similar decrease in the in vivo conduction velocity. Hildebrand et al. (1968) have reported a significant decrease in the mean afferent nerve conduction velocity and provided evidence of an abnormally increased temporal dispersion in individual motor nerve fibres.

Seneviratne and Peiris (1968a) have shown that changes in the size of the response evoked by a constant sub-maximal stimulus of suitable size can be used as a measure of the excitability of the nerve. This technique has been employed in this series to study the effects of hypoxia on the excitability of control and diabetic nerves.

The results obtained in this study confirm the observations of Heinbecker (1929) and Lehmann (1937), that normal peripheral nerves in vitro show a transient phase of hyperexcitability before they are inactivated by anoxia. Our results also provide clear evidence that there are significant differences between the behaviour of control and diabetic nerves during exposure to a hypoxic gas mixture. These differences relate to the extent of inactivation by the hypoxia, and to the time relationships of the early phase of hyperexcitability. These results show that the evoked potentials from the isolated peripheral nerves of alloxan-diabetic rats are more resistant to inactivation by hypoxia than are the potentials evoked from the nerves of healthy rats. This behaviour closely resembles the resistance of the evoked human sensory nerve action potentials of diabetic subjects during ischaemia produced by cuff compression, as shown in Figure 4. This supports the view that any tissue metabolites, produced by mechanical pressure of the cuff or by vascular occlusion, could not have been responsible for the resistance of the diabetic nerve to ischaemia.

Poole $(1956 \mathrm{a}, \mathrm{b})$ observed that subjects with sensory nerve disease did not experience ischaemic or post-ischaemic paraesthesiae, which were a very constant feature of healthy subjects during and after vascular occlusion. These findings were confirmed by Seneviratne and Peiris (1968b) who showed that even diabetic subjects without clinical evidence of neuropathy behaved in the same manner. It has also been shown (Seneviratne and Peiris, 1968a) that the times of onset and duration of ischaemic and post-ischaemic paraesthesiae related well with the observed changes of nerve excitability. The absence of paraesthesiae in the diabetic subject was associated with relatively small rates of change of excitability during the early 

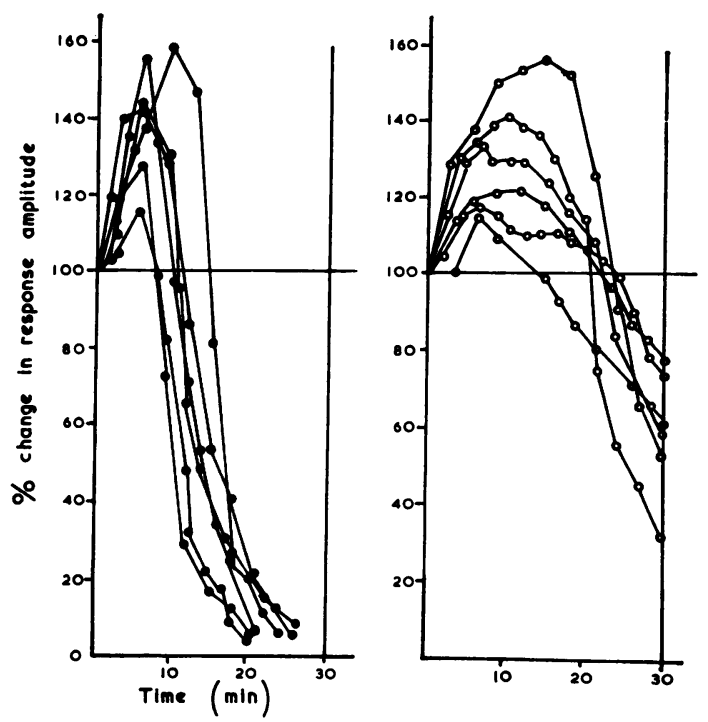

FIG. 4. Change of response size during hypoxia in six experiments on nerves from control rats (filled circles) and nerves from diabetic rats (open circles).

ischaemic and post-ischaemic phases, in contrast with the more marked changes of excitability that occurred in the healthy subjects, all of whom experienced paraesthesiae. Figure 3 and Table I show that the rate of increase of excitability of the isolated peripheral nerve of the healthy rat is significantly greater than that of the diabetic animal. These changes in the hypoxic isolated peripheral nerve are therefore very similar to the comparable changes occurring in the human median nerve during vascular occlusion.

It seems likely that a rapid increase in the excitability of the nerve fibres leads to the spontaneous generation of a large number of impulses. Such a volley of impulses when conducted centrally would presumably be capable of exciting the central synapses which are necessary for the production of paraesthesiae. On this basis, it is suggested that the absence of ischaemic paraesthesiae in diabetic subjects is due to the failure of excitation of these central synapses. This failure could be due to a temporal dispersion of the spontaneously generated potentials resulting from the slow increase of excitability of the nerve.

These findings confirm the views of Merrington and Nathan (1949), Weddel and Sinclair (1947), and Nathan (1958) who were of opinion that ischaemic paraesthesiae were due to the spontaneous generation of impulses in the low threshold group of nerve fibres, whereas Reid (1931) and Bazett and McGlone (1929) believed that the impulses were due to an excitation of the peripheral sense organs.

There is evidence that intracellular potassium is released from nerve fibres during anoxia and that potassium is reabsorbed in the post-anoxic recovery period (Fenn and Gerschman, 1950; Shanes, 1950). Brown and MacIntosh (1939) have shown that direct application of $K$. to the fibre surface causes a repeated discharge of impulses from the nerve fibres even in the absence of an applied stimulus. Paintal (1964) reported that anoxia causes spontaneous firing in muscle spindle afferents due to the stimulation of their sensory endings by the $\mathrm{K}$. which leaks out of the intrafusal muscle fibres and accumulates within the spindle capsules. Shanes (1950) and Huxley and Stämpfli (1951) have demonstrated that a rise of the $K$ - concentration at the nerve fibre surface reduces its resting membrane potential. This depolarization towards the critical membrane voltage produces, in effect, a lowering of the threshold voltage required for stimulation. These changes would explain the hyperexcitability of the nerve fibres seen during the early ischaemic and hypoxic phases in our experiments (Figs. 2 and 4). Maruhash and Wright (1967) have shown that prolongecf exposure to anoxia leads to a failure of membrane energy synthesis and consequent loss of its $\mathrm{Ca} \rightleftharpoons$ binding property. This produces a rapid decrease of 0 membrane resistance and an increase of membrane $\mathbb{D}$ permeability which permits an efflux of intracellulato $\mathbf{K}$. Continued increase of surface $\mathbf{K} \cdot$ concentration leads to depolarization of the membrane to such an extent as to cause failure of action potential generation and conduction block.

Lehmann (1937) and Wright (1947) indicate that conduction block during anoxia occurs within 20 to 30 minutes in mammalian peripheral nerves, a figure in agreement with our findings for nerves from healthy rats. The results we have obtained from the nerves of the diabetic rats are, however, significantly different, these nerves retaining their ability to generate a propagated action potential even at the 30 th minute.

This resistance of the diabetic nerve to inactivation by anoxia could conceivably be due to its ability to maintain its energy synthesis under anoxic conditions by utilizing non-oxidative metabolic pathways.

De Sibrik and O'Doherty (1967) observe that a peripheral nerve seems to have available both the direct oxidative and the glycolytic cycles, and that under varying conditions it could select the pathway from which energy is most economically derived. Shanes $(1948,1950,1951)$ has shown that with in vitro experiments glucose effectively reduces the progressive depolarization of nerve fibres produced 


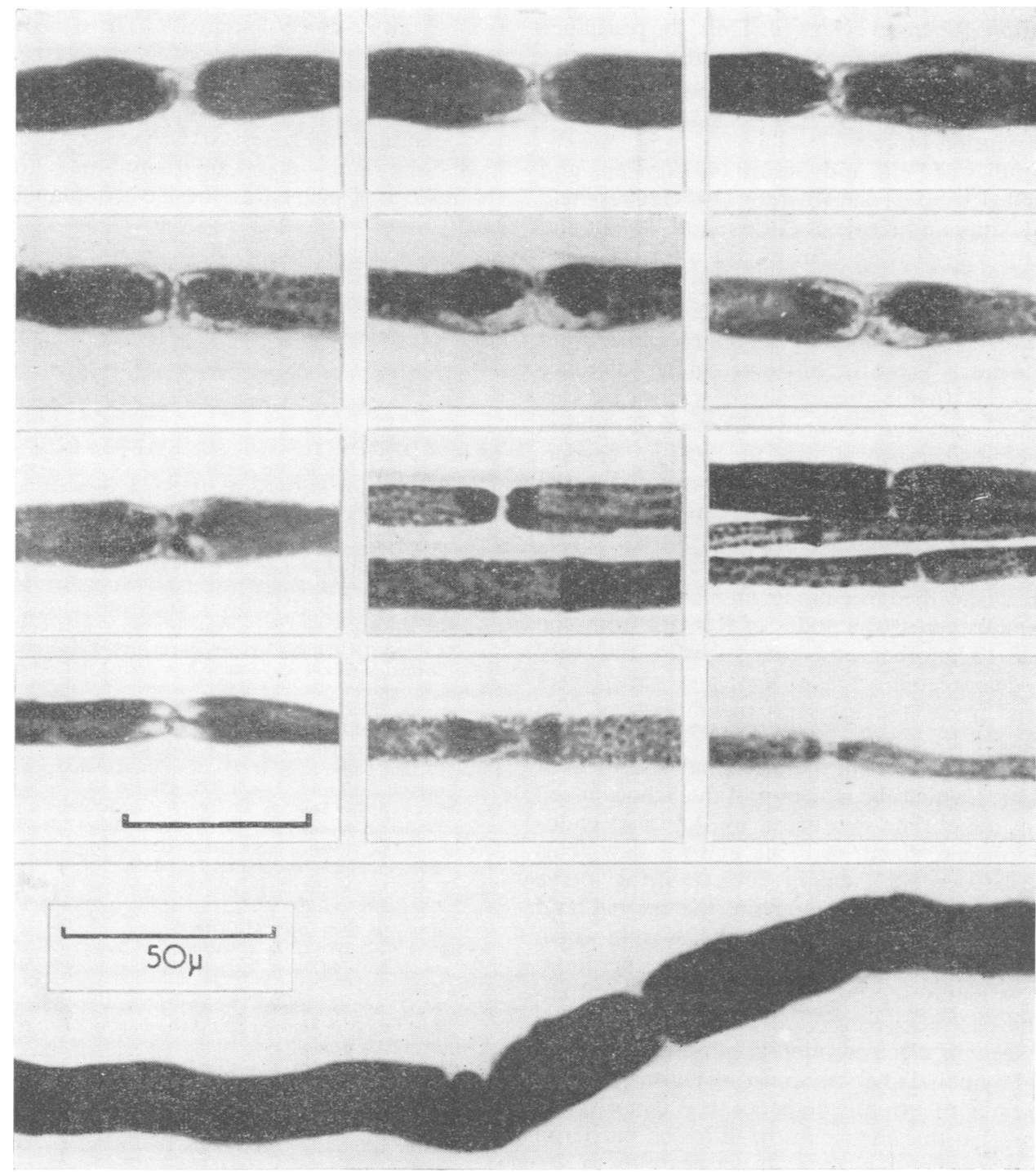

FIG. 5. Upper four rows: early changes of segmental demyelination in fibres from sciatic nerves of diabetic rats. Lower row: single fibre from alloxanized non-diabetic animal. Scale-50 $\mu$.

by anoxia, while Larrabee and Bronk (1952) have shown that anoxia accelerates the process of glycolysis and the rate of glucose uptake by rabbit ganglia. Field and Adams (1964) observed that nerves from alloxan-diabetic animals extract more glucose from the medium than do the nerves of control rats, and Gabbay, Merola, and Field (1966) have shown that diabetic nerves have significantly greater concentration of glucose, sorbitol, and fructose than do the nerves of control rats. These views are consistent with the experimental observations of Steiness (1961b) and Gregersen (1968) that the abnormal resistance of the diabetic nerves to ischaemia is reversible, and that it bore some relationship to the state of control of the diabetes with insulin.

Shanes (1951) has shown that the completeness and rapidity with which washing alone restored functional activity in anoxic fibres, provided evidence 
that surface $\mathrm{K} \cdot$ concentrations suffice to account for the functional changes observed. Thus, the resistance of diabetic nerves to anoxia could also be due to factors which prevent the accumulation of $\mathrm{K} \cdot$ at the nerve fibre surface in quantities sufficient to produce a depolarization block.

The studies of Feng and Gerard (1930); Feng and Liu (1949); Rashbass and Rushton (1949); Crescitelli (1951); Dainty and Krnjević (1955); and Wright and Ooyama (1962) provide clear evidence for the existence of connective tissue diffusion barriers in the nerve, these barriers restricting the free diffusion of ions between the intraneural and extracellular fluid compartments. There is, however, some difference of opinion as to the precise site of such a barrier. Although Causey and Palmer (1963) were of opinion that the epineurium constituted the diffusion barrier, it is now evident that the barrier is not formed by the epineurium but by the perineurium (Huxley and Stämpfli, 1951; Krnjević, 1954; Thomas, 1963; Gamble, 1964). The Schwann cells of myelinated fibres are ensheathed by a basement membrane which is continuous across the nodes of Ranvier from one internode to another and consists of a not very sharply demarcated seam of light and dark layers separated from the plasma membrane of the Schwann cell by a gap of about $250 \AA$. Haftek and Thomas (1968) view the neurilemmal sheath as a continuous elastic tube made up of the Schwann cell basement membrane reinforced by the inner endoneurial collagen sheath of Plenk and Laidlaw. This tube is believed to remain intact during nerve degeneration, serving to contain the axonal and myelin debris and to define the channels within which the Schwann cells proliferate before regeneration. Bischoff (1968) observes that a structural abnormality in the basement membrane is a very prominent change seen in electron-micrographs of peripheral nerves of human diabetics, occurring constantly even in the nerves of juvenile diabetics. It is conceivable, therefore, that this change in the diffusion barrier in diabetic nerves could increase its permeability to $K \cdot$. Such a change would prevent the surface concentration of $\mathrm{K}$ - from reaching the level necessary to produce a depolarization block, thus accounting for the resistance to ischaemia and hypoxia that we have observed.

\section{SUMMARY}

Structural and functional changes in the peripheral nerves of the alloxan-diabetic rat have been studied. Early changes of segmental demyelination were a constant feature in all the nerves.

It has also been shown that the evoked potential from the isolated peripheral nerves of these animals was more resistant to hypoxia than were the responses from healthy control animals. These results have been used to assess the role of $\mathbf{K} \cdot$ in determining the overall excitability changes of normal and diabetic nerves under anoxic conditions.

The nature and genesis of ischaemic paraesthesiae have been discussed and an attempt made to explain the absence of such paraesthesiae in human diabetics.

We wish to thank Messrs. K. S. A. B. Fernando and S. Vairavanathan for their invaluable technical assistance. One of us (K. N.S.) is in receipt of a grant from the Ministry of Scientific Research of the Government of Ceylon.

\section{REFERENCES}

Adrian, E. D. (1930). The effects of injury on mammalian nerve fibres. Proc. roy. Soc. B., 106, 596-618.

Bazett, H. C., and McGlone, B. (1929). A chemical factor in the stimulation of nerves giving temperature sensations. Amer. $J$. Physiol., 90, 278.

Bischoff, A. (1968). Diabet ic neuropathy. Germ.med.Mth., 13, 214-218. Brown, G. L., and MacIntosh, F. C. (1939). Discharges in nerve fibres produced by potassium ions. J. Physiol. (Lond.), 96, 10-11P.

Castaigne, P., Cathala, H. P., Dry, J., and Mastropaolo, C. (1966). Les responses des nerfs et des muscles à des stimulations éléctriques au cours d'une epreuve de garrot ischemique chez l'homme normal et chez le diabetique. Rev. neurol., 115, 61-66.

Causey, G., and Palmer, E. (1953). The epineurial sheath as a barrier to the diffusion of phosphate ions. J. Anat. (Lond.), 87, 30-36.

Crescitelli, F. (1951). Nerve sheath as a barrier to the action of certaino substances. Amer. J. Physiol., 166, 229-240.

Dainty, J., and Krnjević, K. (1955). The rate of exchange of "Na in cak nerves. J. Physiol. (Lond.), 128, 489-503.

De Sibrik, I., and O'Doherty, D. (1967). Peripheral nerve glycolysis ir Wallerian degeneration. Arch. Neurol. (Chic.), 16, 628-634.

Eliasson, S. G. (1964). Nerve conduction changes in experimenta diabetes. J. clin. Invest., 43, 2353-2358.

Feng, T. P., and Gerard, R. W. (1930). Mechanism of nerve asphyxia tion: with a note on the nerve sheath as a diffusion barrier. Proc. Soc. exp. Biol. N.Y., 27, 1073-1076.

- , and Liu, Y. M. (1949). The connective tissue sheath of the nerve as effective diffusion barrier. J. cell. comp. Physiol., 34, 1-16. B114.

Fenn, W. O., and Gerschman, R. (1950). The loss of potassium from frog nerves in anoxia and other conditions. J. gen. Physiol., 33, $195-204$.

Field, R. A., and Adams, L. C. (1964). Insulin response of peripheral nerve. I. Effects on glucose metabolism and permeability. Medicine, 43, 275-279.

Gabbay, K. H., Merola, L. O., and Field, R. A. (1966). Sorbitol pathway. Presence in nerve and cord with substrate accumulation in diabetes. Science, 151, 209-210.

Gamble, H. J. (1964). Comparative electron-microscopic observations on the connective tissues of a peripheral nerve and a spinal nerve root in the rat. J. Anat. (Lond.), 98, 17-25.

Gregersen, G. (1968). A study of the peripheral nerves in diabetic subjects during ischaemia. J. Neurol. Neurosurg. Psychiat., 31, 175-181.

Haftek, J., and Thomas, P. K. (1968). Electron-microscope observations on the effects of localized crush injuries on the connective tissues of peripheral nerve. J. Anat. (Lond.), 103, 233-243.

Heinbecker, P. (1929). Effect of anoxemia, carbon dioxide and lactic acid on electrical phenomena of myelinated fibers of the peripheral nervous system. Amer. J. Physiol., 89, 58-83.

Hildebrand, J., Joffroy, A., Graff, G., and Coërs, C. (1968). Neuromuscular changes with alloxan-hyperglycemia. Arch. Neurol. (Chic.), 18, 633-641.

Huxley, A. F., and Stämpfli, R. (1951). Effect of potassium and sodium on resting and action potentials of single myelinated nerve fibres. J. Physiol. (Lond.), 112, 496-508.

Klebanoff, S. J., and Greenbaum, A. L. (1954). The effect of $p \mathrm{H}$ on the diabetogenic action of alloxan. J. Endocr., 11, 314-.322. 
Krnjević, K. (1954). The connective tissue of the frog sciatic nerve. Quart. J. exp. Physiol., 39, 55-71.

Larrabee, M. G., and Bronk, D. W. (1952). Metabolic requirements of sympathetic neurones. Cold Spr. Harb. Symp. quant. Biol., 17, 245-266.

Lehmann, J. E. (1937). The effect of asphyxia on mammalian A nerve fibres. Amer. J. Physiol., 119, 111-120.

Lovelace, R. E. (1967). Experimental neuropathy in rats made diabetic with alloxan, p. 27 in Proceedings of the International Meeting on Electromyography, Glasgow.

Maruhashi, J., and Wright, E. B. (1967). Effect of oxygen lack on the single isolated mammalian (rat) nerve fiber. J. Neurophysiol., 30, 434-452.

Merrington, W. R., and Nathan, P. W. (1949). A study of postischaemic paraesthesiae. J. Neurol. Neurosurg. Psychiat., 12, $1-18$.

Nathan, P. W. (1958). Ischaemic and post-ischaemic numbness and paraesthesiae. Ibid., 21, 12-23.

Paintal, A. S. (1964). Effects of drugs on vertebrate mechanoreceptors. Pharmacol. Rev., 16, 341-380.

Poole, E. W. (1956a). Ischaemic and post-ischaemic paraesthesiae: normal responses in the upper limb with special reference to the effect of age. J. Neurol. Neurosurg. Psychiat., 19, 148-154.

- (1956b). Ischaemic and post-ischaemic paraesthesiae in polyneuritis. Ijid., 19, 281-288.

Preston, G. M. (1967). Peripheral neuropathy in the alloxan-diabetic rat. J. Physiol. (Lond.), 189, 49P.

Rashbass, C., and Rushton, W. A. H. (1949). The relation of structure to the spread of excitation in frog's sciatic trunk. Ibid., 110, $110-135$

Reid, C. (1931). Experimental ischaemia: sensory phenomena, fibrillary twitchings and effects on pulse respiration and blood pressure. Quart. J. exp. Physiol., 21, 243-251.

Seneviratne, K. N., and Peiris, O. A. (1968a). The effect of ischaemia on the excitability of human sensory nerve. J. Neurol. Neurosurg. Psychiat., 31, 338-347. (1968b). The effect of ischaemia on the excitability of sensory nerves in diabetes mellitus. Ibid., 31, 348-353.

Shanes, A. M. (1948). Metabolic changes of the resting potential in relation to the action of carbon dioxide. Amer. J. Physiol., 153, 93-108.

- (1950). Electrical phenomena in nerve. I. Squid giant axon. $J$. gen. Physiol., 33, 57-74.

- (1951). Potassium movement in relation to nerve activity. Ibid., 34, 795-807.

Steiness, I. B. (1959). Vibratory perception in diabetics during arrested blood flow to the limb. Acta. med. scand., 163, 195-205.

- (1961a). Vibratory perception in non-diabetic subjects during ischaemia, with special reference to the conditions in hyperglycaemia, after carbohydrate starvation and after cortisone administration. Ibid., 169, 17-26.

- (1961b). Influence of diabetic status on vibratory perception during ischaemia. Ibid., 170, 319-338.

Thomas, P. K. (1963). The connective tissue of peripheral nerve: an electron-microscope study. J. Anat. (Lond.), 91, 35-44.

— and Young, J. Z. (1949). Internode lengths in the nerves of fishes. Ibid., 83, 336-350.

- , and Lascelles, R. G. (1966). The pathology of diabetic neuropathy. Quart. J. Med., 35, 489-509.

Weddell, G., and Sinclair, D. C. (1947). 'Pins and needles': observations on some of the sensations aroused in a limb by the application of pressure. J. Neurol. Neurosurg. Psychiat., 10, 26-46.

Wright, E. B. (1947). The effects of asphyxiation and narcosis on peripheral nerve polarization and conduction. Amer. J. Physiol. 148, 174-184.

_- and Ooyama, H. (1962). Role of cations, potassium, calcium and sodium during excitation of frog single nerve fiber. J. Neurophysiol., 25, 94-109. 